\title{
Equilibrium time of scour near structures in plain rivers
}

\author{
Boriss Gjunsburgs, Oskars Lauva, Romans Neilands \\ Water Engineering and Technology Department, Riga Technical University, Azenes 16/20, LV-1048, Riga, Latvia
}

\begin{abstract}
The equilibrium depth of scour is an important parameter for estimation of the foundation depth. The equilibrium depth of scour development under steady flow is depending on time and can be reached in equilibrium time. The aim of the study is to find the equilibrium time near elliptical guide banks at clear water and uniform river bed, which allows to predict the equilibrium depth of scour near structures in flow. The literature analysis shows that there are no methods or formulas to calculate equilibrium time of scour near elliptical guide banks. In formulas for equilibrium time calculation at piers or abutments the different parameters are not taken into consideration: contraction rate of the flow, Froude number, bed layering, sediment movement parameters, local flow modification, relative local and critical velocities ratio and relative depth. The differential equation of the bed sediment movement in clear water was used and method for computing equilibrium time of scour near elliptical guide banks was elaborated. New hydraulic threshold criterion is proposed for calculation of equilibrium time of scour. Computer modeling results were compared with equilibrium time of scour calculated by the presented method and they were in good agreement.
\end{abstract}

Keywords: local scour; equilibrium time; contraction rate of the flow.

\section{Introduction}

In the equilibrium time of scour prediction it is important to know how to calculate the equilibrium depth of scour, in order to predict depth of the bridge foundations (calculate how deep the foundation need to be in the river bed), for example, to appoint the foundation pile length of the structures in river flow. Incorrect prediction depth of foundations for abutments, piers, guide banks or spur dikes can lead to severe damages of the bridge structures and be the reason of considerable economical and financial losses.

The equilibrium time of scour at bridge piers, abutments and spur dikes were studied by Ballio and Orsi [1], Lauchlan et al. [2], Coleman et al. [3], Gjunsburgs and Neilands [4], Dey and Barbhuiya [5], Grimaldi et al. [6], Cardoso and Fael [7], Gjunsburgs et al.[8], Ghani et al. [9] and others.

The threshold criteria are used for equilibrium depth of scour calculation. The threshold criteria, proposed early and known from literature: for calculations when in a 24 hours period the depth of scour increases less than $5 \%$ of the pier diameter [10] or less than 5\% of the flow depth or abutments length [3] or less than 5\% of the $1 / 3$ of the pier diameter [6]. Proposed threshold criterion for equilibrium time of scour is only depending on the size of the bridge structure, and not considering hydraulic parameters of the flow.

Those approaches are conservative, because they do not take into account any flow and geological conditions, near the structure, on which the equilibrium time of scour is depending on. Analysis of the literature shows that there are no methods or formulas to predict equilibrium time of scour near elliptical guide banks. In formulas for equilibrium time of scour at piers or abutments some important parameters of the flow and river bed are not taken into consideration: contraction rate of the flow, Froude number, bed layering, sediment movement parameters, local flow modification, relative local and critical velocities ratio and relative depth.

The aim of the study is to find the equilibrium time of scour near elliptical guide banks at clear water conditions and uniform sand bed in plain rivers.

The differential equation of the bed sediment movement in clear water was used and a method for computing equilibrium time of scour near elliptical guide banks was elaborated. New hydraulic threshold criterion is proposed to determine the equilibrium time of scour.

Corresponding author: Boriss Gjunsburgs. E-mail address: boriss.gjunsburgs@rtu.lv

http://dx.doi.org/10.3846/enviro.2014.077

(C) 2014 The Authors. Published by VGTU Press. This is an open-access article distributed under the terms of the Creative Commons Attribution License, which permits unrestricted use, distribution, and reproduction in any medium, provided the original author and source are credited. 
The test results (with duration of 7 hours) were prolonged by computer modeling till equilibrium stage of scour, using calculation method of scour development in time near elliptical guide banks [11]. Computer modeling results were compared with calculation results of equilibrium time of scour by the presented method and they are in good agreement (Table 2).

\section{Experimental setup}

The tests were carried out in a flume $3.5 \mathrm{~m}$ wide and $21 \mathrm{~m}$ long. Experimental data for the open-flow conditions are presented in Table 1. The tests were carried out under open flow conditions, studying the flow distribution between the channel and the floodplain.

The rigid bed tests were performed for different flow contractions and Froude numbers in order to investigate the velocity and the water level changes in the vicinity of the guide banks and along them. The aim of the sand bed tests was to study the scour process, the changes in the local velocity, the effect of different hydraulic parameters, the contraction rate of the flow, the grain size, stratification of the bed model and the scour development in time.

Table 1. Test data for open flow conditions

\begin{tabular}{llllllll}
\hline Test & $\mathrm{L}, \mathrm{cm}$ & $\mathrm{h}, \mathrm{cm}$ & $\mathrm{V}, \mathrm{cm} / \mathrm{s}$ & $\mathrm{Q}, 1 / \mathrm{s}$ & $\mathrm{Fr}$ & $\mathrm{Re}_{\mathrm{c}}$ & $\mathrm{Re}_{\mathrm{f}}$ \\
\hline L1 & 350 & 7 & 6.47 & 16.60 & 0.078 & 7500 & 4390 \\
L2 & 350 & 7 & 8.58 & 22.70 & 0.103 & 10010 & 6060 \\
L3 & 350 & 7 & 10.3 & 23.60 & 0.124 & 12280 & 7190 \\
L7 & 350 & 13 & 7.51 & 35.48 & 0.066 & 13700 & 9740 \\
L8 & 350 & 13 & 8.74 & 41.38 & 0.075 & 16010 & 11395 \\
\hline
\end{tabular}

The tests were carried out under open flow conditions, studying the flow distribution between the channel and the floodplain.

The openings of the bridge model were 50, 80, 120 and $200 \mathrm{~cm}$. The flow contraction rate $Q / Q_{b}$ (where $Q$ is the flow discharge and $Q_{b}$ is the discharge in the bridge opening under open-flow conditions) varied respectively from 1.56 to 5.69 , depth of water on floodplain was 7 and $13 \mathrm{~cm}$ and the Froude numbers varied from 0.078 to 0.134 . The uniform sand bed tests were carried out under clear-water conditions. The sand was placed $1 \mathrm{~m}$ up and down the contraction of the flume. The mean grain size was 0.24 and $0.67 \mathrm{~mm}$. The tests with stratified bed conditions were performed for contraction rate $Q / Q_{b}=$ 3.66-4.05 (where $Q$ is the flow discharge and $Q_{b}$ is the discharge through the bridge opening under open-flow conditions). Thickness of the layers with different grain size 0.24 and $0.67 \mathrm{~mm}$ with standard deviation were equal 4,7 and $10 \mathrm{~cm}$. The condition that $F r_{R}=F r_{f}$ was fulfilled; where $F r_{R}$ and $F r_{f}$ are the Froude numbers for the plain river and for the flume, respectively. The tests in the flume lasted for 7 hours, the length scale was 50 and the time scale was 7 . With respect to the real conditions, the test time was equal to 2 days. This was the mean duration of time steps into which the flood hydrograph was divided. The development of a scour was examined with different flow parameters in time intervals within one 7-hour step and within two steps of the hydrograph, 7 hours each. The tests were carried out with one floodplain model and one side contraction of the flow, and with two identical or different floodplain models and two sides.

The tests were carried out with one floodplain model and one side contraction of the flow. The dimension of the upper part of an elliptical guide bank, namely the length calculated according to the Latishenkov [12] method and was found to be dependent on the flow contraction rate and the main channel width. The length of the lower part of the guide bank was assumed to be half of the upper part.

\section{Method}

The differential equation of equilibrium for the bed sediment movement in clear-water conditions has the form:

$$
\frac{d W}{d t}=Q_{s}
$$

where: $W$ - the volume of the scour hole at elliptical guide bank, which, according to the test results, is equal to $1 / 5 \pi m^{2} h_{s}{ }^{3}$; $t$ - time; and $Q_{s}$ - the sediment discharge out of the scour hole.

The volume and shape of the scour hole are independent of the contraction rate of the flow [11].

The left-hand part of Eqn. (1) can be written as

$$
\frac{d W}{d t}=\frac{3}{5} \pi m^{2} h_{s}^{2} \frac{d h_{s}}{d t}=a h_{s}^{2} \frac{d h_{s}}{d t},
$$

where: $h_{s}$ - the scour depth; $m$ - the steepness of the scour hole; $a=3 / 5 \pi m^{2}$. 
The sediment discharge was determined by the Levi [13] formula:

$$
Q_{S}=A B \cdot V_{l}^{4} \text { el },
$$

where: $B=m h_{s}$ describes width of the scour hole; $V_{l}-$ the local velocity at the elliptical guide banks with a plain bed; and $A$ - a parameter in the Levi [13] formula.

The discharge across the width of a scour hole before and after the scour is determined as follows:

$$
Q_{f}=Q_{s c},
$$

where: $Q_{f}$ - discharge across the width of the scour hole with a plain bed; $Q_{s c}$ - discharge across the scour hole with a scour depth $h_{s}$. Now we have:

$$
m h_{s} h_{f} V_{l e l}=\left(m h_{s} h_{f}+\frac{m h_{s}}{2} h_{s}\right) \cdot V_{l t e l},
$$

where $m h$ - the width of the scour hole; $h_{f}$ - water depth in the floodplain; $h_{s}$ - the scour depth; and $V_{l t}$ - the local flow velocity at scour depth $h_{s}$.

From Eqn. (5) the local velocity for any depth of scour is

$$
V_{l t_{e l}}=\frac{V_{l}}{1+\frac{h_{s}}{2 h_{f}}},
$$

The critical velocity at the plain bed $V_{0}$ can be determined by the Studenitcnikov [14] formula $V_{0}=3.6 d_{i}^{0.25} h_{f}^{0.25}$, where: $d_{i}$ - grain size of the bed materials.

The critical velocity $V_{0 t}$ for any depth of scour $h_{s}$ and for the flow bended by the bridge crossing embankment is

$$
V_{0 t}=\beta \cdot 3.6 \cdot d_{i}^{0.25} \cdot h_{f}^{0.25}\left(1+\frac{h_{s}}{2 h_{f}}\right)^{0.25},
$$

where: $\beta$ - coefficient of critical velocity reduction near structure, because of flow circulation.

At a plain river bed the formula for $A=A_{l}$ reads Eqn. (3)

$$
A=\frac{5.62}{\gamma}\left(1-\frac{\beta V_{0}}{V_{l e l}}\right) \frac{1}{d_{i}^{0.25} \cdot h_{f}^{0.25}},
$$

where: $\gamma$ - specific weight of the sediments.

The parameter $A$ depends on the scour, local velocity $V_{l}$, critical velocity $\beta V_{0}$ and grain size of the bed material changing during the floods:

$$
A_{i}=\frac{5.62}{\gamma}\left[1-\frac{\beta V_{0}}{V_{l e l}}\left(1+\frac{h_{s}}{2 h_{f}}\right)^{1.25}\right] \cdot \frac{1}{d_{i}^{0.25} \cdot h_{f}^{0.25}\left(1+\frac{h_{s}}{2 h_{f}}\right)^{0.25}},
$$

where: $\frac{\beta V_{o t}}{V_{\text {ltel }}}=\frac{\beta V_{o}}{V_{\text {lel }}}\left(1+\frac{h_{s}}{2 h_{f}}\right)^{1.25}$.

Then we replace $V_{l}$ in Eqn. (3) with the local velocity at any depth of scour $V_{l t}$ from Eqn. (6). The parameter $A$ in Equation (3) is replaced with the parameter $A_{i}$ from Eqn. (9). The sediment discharge upon development of the scour is

$$
Q_{s}=A_{i} \cdot m h_{s} \cdot V_{l t e l}^{4}=b \frac{h_{s}}{\left(1+\frac{h_{s}}{2 h_{f}}\right)^{4}},
$$

where: $b=A_{i} m V_{l_{e l}}{ }^{4}$

The hydraulic characteristics, such as the contraction rate of the flow, the velocities $\beta V_{0}$ and $V_{l}$, the grain size in different bed layers, the sediment discharge, and the depth, width and volume of the scour hole, varied during the floods.

Taking into account Equations (2) and (10), the differential Eqn. (1) can be written in the form 


$$
a h_{s}^{2} \frac{d h_{s}}{d t}=b \frac{h_{s}}{\left(1+\frac{h_{s}}{2 h_{f}}\right)^{4}},
$$

After separating the variables and integration of Eqn. (11), we have:

$$
\begin{gathered}
t=D_{i} \int_{x_{1}}^{x_{2}} h_{s}\left(1+\frac{h_{s}}{2 h_{f}}\right)^{4} d h_{s}, \\
D_{i}=\frac{a}{b}=\frac{3}{5} \frac{\pi \cdot m \cdot}{A_{i} \cdot V_{l e l}^{4}},
\end{gathered}
$$

where: $x_{1}=1+h_{s 1} / 2 h_{f}$ and $x_{2}=1+h_{s 2} / 2 h_{f}$ are relative depths of scour.

After integration with new variables $x=1+h_{s} / 2 h_{f}, h_{s}=2 h_{f}(x-1)$ and $d h_{s}=2 h_{f} d x$ we obtain

$$
t=4 D_{i} h_{f}^{2}\left(N_{i}-N_{i-1}\right) \text {, }
$$

where: $N_{i}=1 / 6 x_{i}^{6}-1 / 5 x_{i}^{5}, N_{i-1}=1 / 6 x_{i-1}{ }^{6}-1 / 5_{x i-1}{ }^{5}, \quad x=1+h_{s} / 2 h_{s}$ are the relative depths of scour.

Using the equilibrium depth of scour in Eqns (9), (13) and (14) it is possible to find equilibrium time of scour near elliptical guide banks

$$
t_{\text {equil }}=4 D_{\text {equil. }} \cdot h_{f}^{2}\left(N_{\text {equil. }}-N_{i-1}\right),
$$

The sequence to calculate the equilibrium time of scour is the next:

The equilibrium depth of scour at elliptical guide banks is found [11]:

$$
h_{\text {equil }}=2 h_{f}\left[\left(\frac{V_{l e l}}{\beta V_{o}}\right)^{0.8}-1\right] \cdot k_{\alpha} \cdot k_{m},
$$

where: $V_{0}=3.6 d_{i}^{0.25} h_{f}^{0.25}$ is the critical velocity at the plain bed; $k_{\alpha}-$ a coefficient depending on the flow crossing angle; and $k_{m}-$ a coefficient depending on the side-wall slope of guide banks.

Using value $h_{\text {equil }}$ it is possible to find values $A_{\text {equil }}, D_{\text {equil }}, N_{\text {equil }}$ and finally $t_{\text {equil }}$.

When local velocity $V_{l t}$ becomes equal to critical velocity $\beta V_{0 t}, A_{\text {equil }}=0, D_{\text {equil }}=\infty$ and $t_{\text {equil }}=\infty$, criteria to evaluate threshold is needed to appoint to calculate equilibrium time of scour.

\section{Results}

At the head of the elliptical guide bank, we observe the concentration of streamlines, a sharp drop in water level, and a local increase in the velocity. Locally modified flow near the guide banks is forming the scour hole. Fig. 1 illustrates the scour depth $h_{s}$ and respective variations in the local $V_{l t}$ and critical $\beta V_{0 t}$ velocities, as measured experimentally and calculated in steady flow and layer with uniform sand. With the scour depth increase, the local velocity is reducing and the critical one is increasing (Fig. 1).

Ratio of critical velocity to local one at the head of elliptical guide bank is accepted as threshold criteria in equilibrium time of scour calculation. According to computer modelling results the scour stops when local velocity $V_{l t}$ becomes equal to critical velocity $\beta V_{0 t}$ or ratio of those velocities becomes equal to 1 , and equilibrium is equal to infinity. The threshold criterion checked and accepted equal to $\beta V_{o t} / V_{l t}=0,985222$ for calculation equilibrium time of scour.

$$
\frac{\beta V_{\text {ot }}}{V_{\text {ltel }}}=\frac{\beta V_{o}}{V_{\text {lel }}}\left(1+\frac{h_{\text {equil. }}}{2 h_{f}}\right)^{1.25}=0,985222 \text {. }
$$




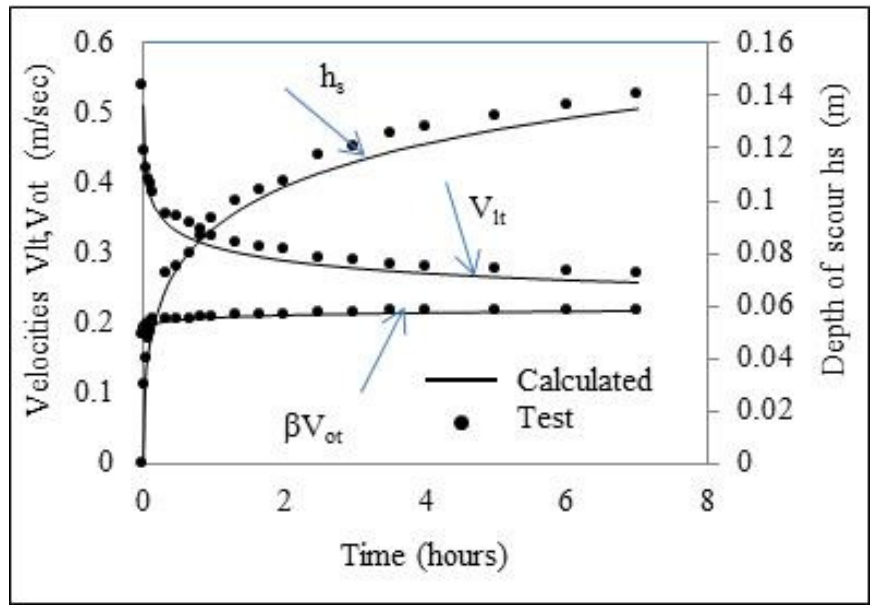

Fig. 1. Changes in scour depth and in the local and critical velocities $V_{l t}$ and $\beta V_{o t}$ varying with time under steady flow with one-sand layer, test EL 6 .

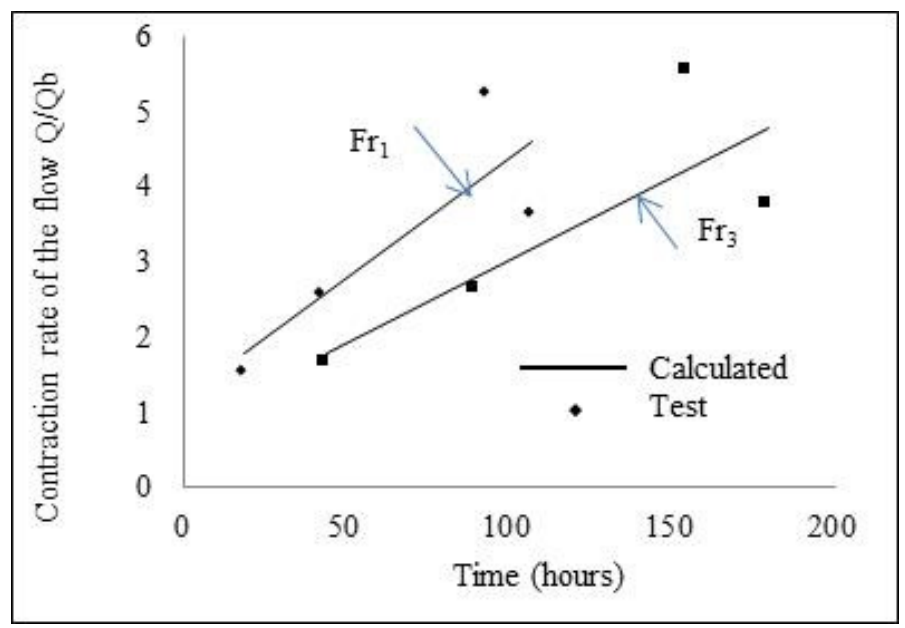

Fig. 2. Dependence of the equilibrium time of scour from the contraction rate of the flow $Q / Q_{b}$.

Theoretical analysis of the method presented and test results confirmed the influence contraction rate of the flow, Froude number, bed layering, relative local and critical velocities ratio, relative depth of scour on equilibrium time of scour.

The ratio of the critical velocity to local one $\beta V_{0} / V_{l}$ is depending on contraction rate of the flow $\mathrm{Q} / \mathrm{Q}_{\mathrm{b}}$.

With contraction rate of the flow the equilibrium time of scour is increasing (Fig. 2).

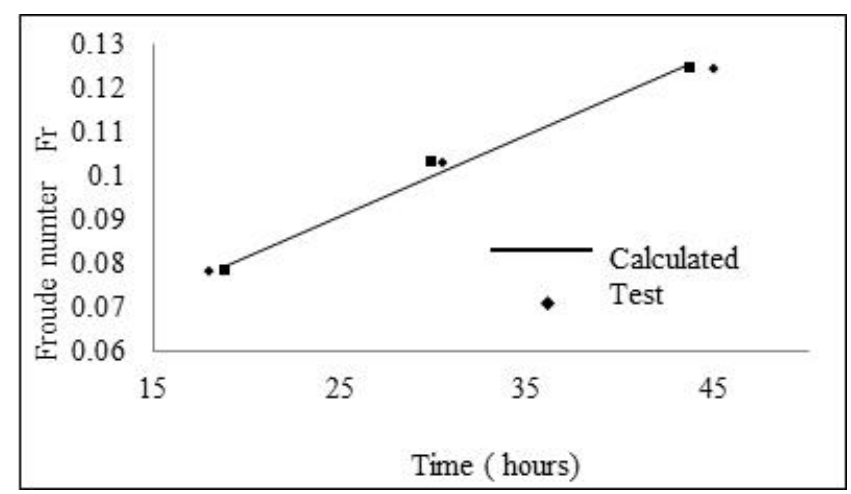

Fig. 3. Froude number influence on equilibrium time of scour

With increase of the Froude number of the flow the equilibrium time of scour is increasing (Fig. 3). 


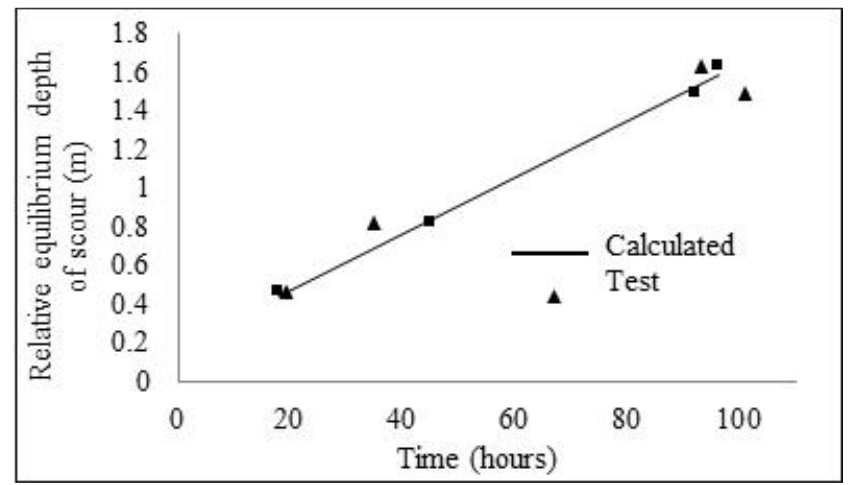

Fig. 4. Relative equilibrium depth of scour versus equilibrium time of scour.

To reach greater relative equilibrium depth of scour greater equilibrium time is needed (Fig. 4).

Table 2. Comparison equilibrium time of scour calculated by computer modelling and by proposed methods

\begin{tabular}{|c|c|c|c|c|c|c|c|c|}
\hline TEST & $\mathrm{Q} / \mathrm{Q}_{\mathrm{b}}$ & $\mathrm{D}$ & $\mathrm{N}_{\mathrm{i}}-\mathrm{N}_{\mathrm{i}-1}$ & $\mathrm{t}_{\text {comp. }}$ & $\mathrm{t}_{\text {form. }}$ & $\mathrm{t}_{\mathrm{c}} / \mathrm{t}_{\mathrm{f}}$ & $\mathrm{bV}_{\mathrm{ot}} / \mathrm{V}_{\mathrm{lt}}$ & $\mathrm{Fr}$ \\
\hline EL4 & 3.66 & 166.54 & 1.37121 & 92.1 & 107.42 & 0.857382 & 0.985222 & 0.078 \\
\hline EL7 & 2.6 & 450.468 & 0.198985 & 45 & 42.96 & 1.047486 & 0.985222 & 0.078 \\
\hline EL10 & 1.56 & 957.28 & 0.041959 & 18 & 18.89 & 0.952885 & 0.985222 & 0.078 \\
\hline EL5 & 3.87 & 47.48666 & 4.089851 & 100.8 & 91.35798 & 1.103352 & 0.985222 & 0.103 \\
\hline EL8 & 2.69 & 130.7591 & 1.553792 & 90 & 95.57231 & 0.941695 & 0.985222 & 0.103 \\
\hline EL11 & 1.66 & 619.5014 & 0.102817 & 30.5 & 29.96214 & 1.017951 & 0.985222 & 0.103 \\
\hline EL12 & 1.67 & 467.5394 & 0.198961 & 45 & 43.75755 & 1.028394 & 0.985222 & 0.1243 \\
\hline
\end{tabular}

Using threshold criteria Eqn. (17), equilibrium depth of scour $h_{\text {equil }}$ Eqn. (16), $A_{\text {equil }}, D_{\text {equil }}, N_{\text {equil }}$ and finally equilibrium time $t_{\text {equil }}$ Eqn. (15) is calculated. Computer modelling of scour development in time near elliptical guide banks was used [11] to prolong test results to equilibrium depth and time of scour. Comparison equilibrium times calculated by computer modelling and by Eqn. (15) have been made; results are in good agreement (Table 2).

\section{Conclusions}

The flow pattern at the head of the elliptical guide banks is modified, the concentration of streamlines, a sharp drop in water level, a local increase in the velocity, vortex structures, circulation and scour hole was observed. Locally modified flow near the head of the guide banks is forming the scour hole.

The equilibrium depth of scour development under steady flow is depending on time and can be reached in equilibrium time. An analysis of the literature shows that there are no methods or formulas to calculate equilibrium time of scour near elliptical guide banks.

The differential equation of the bed sediment movement in clear water was used and a method for computing equilibrium time of scour near elliptical guide banks was elaborated. The test results (with duration of 7 hours) were prolonged by computer modelling till equilibrium stage of scour, using method of calculation scour development in time near elliptical guide banks [11]. With the scour depth increase, the local velocity is reducing and the critical one is increasing. According to the computer modelling, the scour stops when the local velocity $V_{l t}$ becomes equal to the critical velocity $\beta V_{0 t}$ or ratio of those velocities becomes equal to 1 , if that happens $A_{\text {equil }}=0, D_{\text {equil }}=\infty$ and equilibrium time goes to infinity $t_{\text {equil }}=\infty$. The new threshold criterion as $\beta V_{0 t} / V_{l t}=0.985222$ is checked and accepted for equilibrium time of scour calculation. Using the new threshold criteria in Equation (17), $h_{\text {equil }}, A_{\text {equil }}, D_{\text {equil }}, N_{\text {equil }}$ and finally $t_{\text {equil }}$ by Eqn. (15) is calculated.

Computer modelling results were compared with equilibrium time of scour, calculated by the method presented Eqn. (15) and they are in good agreement (Table 2). 


\section{References}

[1] Ballio, F.; Orsi, E. 2001. Time evolution of scour around bridge abutments, Water Engineering Resources 2(4): $243-259$.

[2] Lauchlan, C. S.; Coleman, S. E.; Melville, B. W. 2001. Temporal scour development at bridge abutments, in Proceedings of the XXIX Congress of the International Association of Hydraulics Research, Beijing, 738-745.

[3] Coleman, S. E.; Lauchlan, C. S.; Melville, B. W. 2003. Clear water scour development at bridge abutments, Journal of Hydraulic Research 42(5): 521531. http://dx.doi.org/10.1080/00221680309499997

[4] Gjunsburgs, B.; Govsha, E.; Neilands, R. 2006. Scour development at elliptical guide banks during multiple floods, in Harmonizing the demands of art and nature in hydraulics, $32^{\text {nd }}$ Congress of IAHR (CD), Italy, Venice, 1-6. July, 2007, 1-10.

[5] Dey, S.; Barbhuiya, A. K. 2005. Time variation of scour at abutments, Journal of Hydraulic Engineering 131(1): 11-23. http://dx.doi.org/10.1061/(ASCE)0733-9429(2005)131:1(11)

[6] Grimaldi, C.; Gaudio, R.; Cardoso, A. H.; Calomino, F. 2006. Local scouring at bridge piers and abutments: time evolution and equilibrium, in Proc. River Flow 2006, Ferreira, Alves, Leal \& Cordoso (eds), (1), Lisbon, Portugal, 1657-1664.

[7] Cardoso, A. H.; Fael, C. M. S. 2010. Time to equilibrium scour at vertical wall bridge abutments, in Proceedings of the ICE-Water Management 163(10): 509-513. http://dx.doi.org/10.1680/wama.900038

[8] Gjunsburgs, B.; Jaundzems, G.; Govsha, E. 2010. Assessment of flood damage risk for abutments in river floodplains, in River Flow 2010 - Dittrich, Koll, Aberle \& Geisenhainer, 1185-1192.

[9] Ghani, A. A.; Azamathullah, H. M.; Mohammadpour, R. 2011. Estimating time to equilibrium scour at long abutment by using genetic programming, in $3^{\text {rd }}$ International Conference on Managing Rivers in the $21^{\text {st }}$ Century: Sustainable Solutions for Global Crisis of Flooding, Pollution and Water Scarcity, Rivers 2011, $6^{\text {th }}-9^{\text {th }}$ December 2011, Penang, Malaysia, 369-374.

[10] Melville, B. W.; Chiew, Y. M. 1999. Time scale for local scour at bridge piers, Journal of Hydraulic Engineering 125(1): 59-65. http://dx.doi.org/10.1061/(ASCE)0733-9429(1999)125:1(59)

[11] Gjunsburgs, B.; Govsha, E.; Neilands, R. 2006. Local Scour at the Elliptical Guide Banks, in ICSE-3, $3^{\text {rd }}$ International Conference on Scour and Erosion, Netherland, Amsterdam, 1.-3. November, 2006, 120-128.

[12] Latishenkov, A. M. 1960. Questions of artificially contracted flow. Moscow: Gostroizdat (in Russian).

[13] Levi, I. I. 1969. Dynamics of River Flow. Moscow: Gidrometeoizdat (in Russian).

[14] Studenitchnikov, B. 1964. Scouring capacity of the flow and methods of channel calculation. Moscow: Stroiizdat (in Russian). 